\title{
STRUKTUR SEDIMEN DAN SEBARAN KERANG PISAU (Solen lamarckii) DI PANTAI KEJAWANAN CIREBON JAWA BARAT
}

\author{
Subiyanto, Agus Hartoko, Khoerul Umah* \\ Jurusan Perikanan, Fakultas Perikanan dan Ilmu Kelautan, Universitas Diponegoro \\ Jl. Prof. H. Soedharto, SH. Tembalang Semarang 50275 Telp/Fax (024) 76480685
}

\begin{abstract}
Abstrak
Struktur komunitas biota dipengaruhi oleh faktor ekologis seperti sedimen dasar perairan. Jenis sedimen digunakan sebagai indikasi untuk menentukan pola hidup, ketiadaan dan tipe organisme pada Gastropoda dan Bivalvia. Keragaman tekstur sedimen dasar perairan yang dimiliki Pantai Kejawanan mengakibatkan terjadinya pola distribusi biota yang hidup di pantai tersebut. Salah satu biota di pantai ini adalah kerang pisau. Penelitian ini menggunakan metode deskriptif dengan pengambilan sampel secara random sampling. Penelitian dilakukan dengan tujuan untuk mengetahui pengaruh struktur sedimen terhadap sebaran kerang pisau di Pantai Kejawanan. Hasil penelitian menunjukan jenis sedimen yang ada di Pantai Kejawanan adalah jenis pasir berlumpur (medium sand) dengan persentase pasir antara 75,23 - 96,04 \% dan lumpur antara 3,96 - 22,74 \%. Sebaran kerang pisau di Pantai Kejawanan bersifat mengelompok dan hanya ditemukan pada jenis sedimen tertentu. Pada jenis sedimen pasir berlumpur dengan persentase kandungan pasir yang tinggi kepadatan kerang juga tinggi, sedangkan pada persentase kandungan pasir yang rendah kepadatannya rendah.
\end{abstract}

Kata kunci: Sedimen, Kerang Pisau, Pantai Kejawanan.

\begin{abstract}
Abstrak
Structure of benthic community is influenced by ecological factors such as sediments. Sediment types are an indicate to determined the pattern of life, the absence and the type of organisms on types of Gastropods and Bivalves. Variety of bottom sediments texture at Kejawanan Beach cause the distribution pattern of biota that lived on the coast. One of the biota at coastal sediment is a razor clam.. This research uses descriptive method with random sampling technique. Research is conducted to obtain the information of structure sediment and distribution of razor clam in Kejawanan Beach. The result showed that the sediment type in Kejawanan Beach was kinds of muddy sand (medium sand) with sand percentages between $75,23-96,04 \%$ and mud between 3,96-22,74\%. The spread of razor clams at Kejawanan Beach were clustered on a particular type of sediment. The type of muddy sediment with a high sand content percentage, the density of shell was high also, while the low sand content precentage the density was low.
\end{abstract}

Key words: Sediment, Razor Clam, Kejawanan Beach. 


\section{Pendahuluan}

Sedimen dasar perairan mempunyai peranan penting bagi kehidupan Gastropoda dan Bivalvia. Menurut Nybakken (1982) dalam Riniatsih dan Kushartono (2009) umumnya Gastropoda dan Bivalvia hidup pada sedimen untuk menentukan pola hidup, ketiadaan dan tipe organisme. Ukuran sangat berpengaruh dalam menentukan kemampuan sedimen tersebut menahan sirkulasi air. Bahan organik dan tekstur sedimen menentukan keberadaan Gastropoda dan Bivalvia, dimana sedimen merupakan tempat untuk hidup, sedangkan bahan organik mempengaruhi fitoplankton yang merupakan sumber makanan.

Jenis sedimen berpengaruh terhadap kandungan bahan organik. Menurut Hartoko (2010) Pada jenis sedimen berpasir memiliki kandungan bahan organik rendah, hal ini disebabkan pada sedimen tersebut memungkinkan terjadinya oksidasi yang baik akibat adanya pore water yang lebih besar, sehingga bahan organik akan cepat habis. Sebaliknya pada jenis sedimen liat yang mempunyai tekstur lebih halus, kandungan bahan organik tergolong tinggi.

Kerang pisau (Solen lamarckii) merupakan salah satu jenis moluska dari kelas Bivalvia yang nilai ekonomisnya tinggi (Nurjanah et al., 2008). Biota ini bersembunyi atau menggali secara vertikal pada sedimen dan akan sedikit keluar pada saat surut. Kerang tersebut banyak ditemukan di sepanjang perairan Pantai Selatan Pamekasan, Madura dengan ciri pantai yang landai dan datar sehingga jika air laut surut jarak air dengan garis pantai dapat mencapai 200 300 m (Nurjanah et al., 2008; Abroni, 2012).

Pantai Kejawanan memiliki topografi pantai yang landai dengan perairan tenang dan gelombang yang tidak terlalu besar. Arah angin dominan sepanjang tahun yang mempengaruhi pembentukan gelombang laut yang menuju ke arah pantai Teluk Cirebon. (Dinas PPN Kejawanan, 2009). Wilayah pantai ini selain mempunyai ciri fisik seperti di atas, juga memiliki kesamaan dengan wilayah Pantai Madura dimana terdapat kerang pisau. Pada beberapa lokasi di Pantai Kejawanan terindikasi dijumpainya kerang pisau. Memperhatikan keadaan tersebut perlu dilakukan penelitian guna mendapatkan informasi yang lebih mendalam tentang kondisi sumberdaya kerang pisau di wilayah Pantai Kejawanan.

Penelitian ini bertujuan untuk mengetahui jenis sedimen di Pantai Kejawanan, mengetahui sebaran kerang pisau di Pantai Kejawanan dan mengetahui pengaruh jenis sedimen terhadap sebaran kerang pisau di Pantai Kejawanan. Manfaat dari penelitian diharapkan dapat memberikan informasi mengenai pengaruh jenis sedimen terhadap sebaran kerang pisau dan data hasil penelitian diharapkan dapat menjadi landasan untuk pengelolaan sumberdaya kerang selanjutnya.

\section{Materi dan Metode Penelitian}

\section{A. Materi Penelitian}

Materi yang digunakan dalam penelitian ini adalah sampel sedimen dan sampel kerang pisau yang berasal dari Pantai Kejawanan serta data citra Satelit Landsat ETM. Sampel dan data tersebut digunakan untuk analisis struktur serta sebaran kerang pisau dan analisis peta persebaran kerang. Penelitian ini juga mengukur parameter fisika perairan seperti suhu air, salinitas dan $\mathrm{pH}$.

Alat-alat yang digunakan dalam penelitian ini adalah GPS (Global Positioning System) yang digunakan untuk menentukan lokasi titik sampling. Untuk pencarian kerang digunakan alat yaitu cangkul. Sedangkan untuk tempat sampel berupa ember dan plastik. Kuadran transek digunakan sebagai alat pembatas pengambilan sampel pada titik sampel. Untuk melakukan pengukuran salinitas digunakan refraktometer dan untuk pengukuran suhu digunakan termometer air raksa. Pipet tetes dipakai untuk meneteskan sampel air pada pengujian salinitas menggunakan refrakrometer. Alat tulis digunakan untuk mencatat data hasil penelitian. Pada perhitungan jarak lokasi pengambilan sampel digunakan tali rafia. Sedangkan pada perhitungan panjang dan berat kerang digunakan alat yaitu jangka sorong dan timbangan elektrik. Untuk identifikasi biota menggunakan alat yaitu mikroskop dan slide glass, sedangkan untuk buku identifikasi yang digunakan adalah buku identifikasi Bivalve menurut Poutiers (1998). Kegiatan penelitian ini didokumentasikan dengan menggunakan kamera digital.

\section{B. Metode Penelitian}

Metode yang digunakan dalam penelitian ini adalah metode deskriptif, yaitu suatu bentuk penelitian yang ditujukan untuk mendeskripsikan fenomena-fenomena yang ada, baik itu fenomena alamiah maupun fenomena buatan manusia (Sukmadinata, 2006). Metode pengambilan sampel menggunakan metode random sampling. Random sampling adalah suatu metode pemilihan ukuran sampel dimana setiap anggota populasi mempunyai peluang yang sama untuk dipilih menjadi anggota sampel (Umar, 1999). Tahapan penelitian terdiri dari :

\section{Penentuan lokasi sampling}

Pengambilan sampel dilakukan di sekitar Pantai Kejawanan pada 2 stasiun yang berbeda. Masing-masing stasiun terdiri dari 9 plot dengan ukuran 10x10 m. Pada tiap plot dibagi menjadi subplot dengan ukuran 1x1 m, sehingga didapatkan 100 subplot. Dari 100 subplot tersebut kemudian dipilih 5 subplot secara acak untuk selanjutnya dilakukan pengambilan sampel kerang dan sampel sedimen.

\section{Pengambilan sampel lapangan}

Metode pengambilan sampel diawali dengan pencatatan titik koordinat dengan menggunakan GPS (Global Positioning System). Kemudian dilanjutkan dengan pengukuran parameter fisika perairan (suhu air, salinitas dan $\mathrm{pH}$ ). Pengukuran suhu dengan menggunakan termometer air raksa, pengukuran salinitas menggunakan refraktometer dan pengukuran $\mathrm{pH}$ menggunakan $\mathrm{pH}$ paper. Cara pengambilan sampel kerang menggunakan alat yaitu cangkul, dengan 
Kedalaman tanah yang dibutuhkan untuk pencangkulan antara $25-30 \mathrm{~cm}$. Sampel kerang yang didapatkan selanjutnya dibersihkan dan dimasukan kedalam plastik sampel yang berisi formalin $4 \%$. Untuk sampel sedimen diambil dengan cara mengkomposit 5 subplot dari masing-masing plot penelitian. Kemudian dimasukan kedalam plastik sampel. Sampel sedimen tersebut selanjutnya dianalisis di laboratorium untuk diamati jenis substrat dan nilai kandungan bahan organiknya. Sedangkan untuk sampel kerang dihitung kepadatan beserta ukuran panjang dan berat. Selain pengambilan sampel kerang dan sampel sedimen dilakukan juga pengambilan organisme bentik lain yang ditemukan di lokasi penelitian.

\section{Identifikasi biota}

Identifikasi biota dilakukan melalui pengamatan bentuk, warna cangkang serta pola pertumbuhannnya. Pada identifikasi ini digunakan buku identifikasi Bivalve menurut Poutiers (1998). Selain identifikasi, pada sampel kerang pisau yang didapatkan dilakukan pula pengukuran panjang dan berat. Pengukuran panjang menggunakan jangka sorong dan pengukuran berat menggunakan timbangan elektrik.

Setelah didapatkan jenis spesies dan ukuran panjang berat, sampel kerang selanjutnya dihitung kelimpahannya. Kelimpahan suatu organisme dalam suatu perairan dinyatakan sebagai jumlah individu per area (Odum, 1971 dalam Abroni, 2012) yang dirumuskan sebagai berikut :

$$
A=\frac{X i}{n i}
$$

Keterangan :

A : Kelimpahan (individu $/ \mathrm{m}^{2}$ )

$\mathrm{Xi}$ : Jumlah individu yang ditemukan (individu)

ni : Jumlah luasan kuadran transek $\left(\mathrm{m}^{2}\right)$

\section{Analisis struktur sedimen}

\section{a. jenis sedimen}

Pengolahan data jenis sedimen menggunakan metode grain size analysis menurut Buchanan (1974) dalam Abroni (2012). Pada penentuan jenisnya digunakan skala AASTHO (American Association of State Highway and Transportation Officials) dengan klasifikasi :

Gravel : > $2 \mathrm{~mm}$

Sand : $0,1-2 \mathrm{~mm}$

Silt $\quad: 0,01-0,1 \mathrm{~mm}$

Clay : $<0,01 \mathrm{~mm}$

\section{b. kandungan bahan organik}

Pengujian kandungan bahan organik dilakukan dengan menggunakan metode Gravimetri (Jaya et al., 1994 dalam Indrawati, 2013)

\section{Pengolahan data citra Satelit Landsat ETM}

Pengolahan data citra satelit menggunakan metode geostatistik kriging. Metode geostatistik kriging adalah suatu metode penentuan nilai titik pada permukaan bumi dengan cara memplotkan skala dan proyeksi data lintang serta bujur yang sudah diolah dalam sistem transformasi numerik berdasarkan posisi koordinatnya (Hartoko, 2002 dalam Abroni, 2012). Data yang digunakan dalam pengolahan ini antara lain: data koordinat Pantai Kejawanan, data kepadatan kerang pisau, data jenis sedimen dan data kandungan bahan organik.

\section{Analisis data}

Analisis data dilakukan dengan menggunakan uji statistik yaitu uji korelasi dan uji regresi. Tujuannya untuk mengetahui hubungan antara parameter-parameter yang diteliti antara lain korelasi antara panjang dengan berat kerang serta kepadatan dengan parameter lingkungan yang mempengaruhi. Dalam uji ini akan ditentukan koefisien korelasi dengan kriteria :

1. $0 \quad$ : Tidak ada korelasi antara dua variabel

2. $>0-0,25:$ Korelasi sangat lemah

3. $>0,25-0,5:$ Korelasi cukup

4. $>0,5-0,75:$ Korelasi kuat

5. >0,75-0,99: Korelasi sangat kuat

$6 . \quad 1 \quad$ : Korelasi sempurna (Sarwono, 2006).

Pada penentuan hipotesis untuk mengetahui ada tidaknya hubungan antara pengaruh parameter lingkungan terhadap kepadatan kerang terdapat pendugaan bahwa jenis sedimen dan kandungan bahan organik mempengaruhi kepadatan kerang. Semakin tinggi persentase pasir dan kandungan bahan organik pada sedimen, semakin tinggi kepadatan yang ditemukan. Sehingga hipotesisnya:

$\mathrm{H}_{0}$ : Tidak terdapat hubungan antara jenis sedimen dan kandungan bahan organik terhadap kepadatan kerang.

$\mathrm{H}_{1}$ : Terdapat hubungan antara jenis sedimen dan kandungan bahan organik terhadap kepadatan kerang.

Kaidah pengambilan keputusan untuk menguji hipotesis tersebut adalah dengan ketentuan sebagai berikut : 
Jika F hitung < F Tabel (5\%) maka terima $\mathrm{H}_{0}$ dan tolak $\mathrm{H}_{1}$. Jika $\mathrm{F}$ hitung $\geq \mathrm{F}$ tabel $(5 \%)$ maka tolak $\mathrm{H}_{0}$ dan terima $\mathrm{H}_{1}$.

3. Hasil dan Pembahasan

\section{Gambaran umum lokasi penelitian}

Pantai Kejawanan terletak di Kelurahan Lemahwungkuk Kecamatan Lemahwungkuk, Cirebon, Jawa Barat. Pantai ini terletak pada $06^{\circ} 44^{\prime} 14$ " LS dan 108 34'54” BT. Batas administratif Pantai Kejawanan adalah sebagai berikut :

Sebelah utara : Laut Jawa

Sebelah timur : Laut Jawa

Sebelah selatan : Cirebon Selatan

Sebelah barat : Kota Cirebon

(Dinas PPN Kejawanan, 2009).

Pantai Kejawanan memiliki topografi pantai yang landai dengan perairan tenang dan gelombang yang tidak terlalu besar. Arah angin dominan sepanjang tahun yang mempengaruhi pembentukan gelombang laut yang menuju ke arah pantai Teluk Cirebon. Menurut hasil penelitian Rifni (2010) Perairan Pantai Kejawanan memiliki tipe pasang surut campuran condong harian ganda (mixed tide predominantly semi diurnal) yaitu tipe pasang surut dimana dalam satu hari terjadi dua kali air pasang dan dua kali air surut, tetapi tinggi dan periodenya berbeda. Arus di perairan tersebut dipengaruhi angin muson dengan gelombang tidak terlalu besar karena topografi perairan utara yang tenang. Proses sedimentasi di Perairan Kejawanan dipengaruhi oleh aliran Sungai Cimanuk, Tangkal dan Pegambiran (Irfan, 2011).

Identifikasi biota

Hasil identifikasi biota menunjukan kerang pisau yang ditemukan di Pantai Kejawanan termasuk dalam species Solen lamarckii. Klasifikasi Solen lamarckii menurut Deshayes (1839) dalam Poutiers (1998) adalah sebagai berikut :

$\begin{array}{ll}\text { Kingdom } & \text { : Animalia } \\ \text { Filum } & \text { : Mollusca } \\ \text { Kelas } & \text { : Bivalvia } \\ \text { Ordo } & \text { : Veneroida } \\ \text { Famili } & \text { : Solenidae } \\ \text { Genus } & \text { : Solen } \\ \text { Species } & \text { : Solen lamarckii }\end{array}$

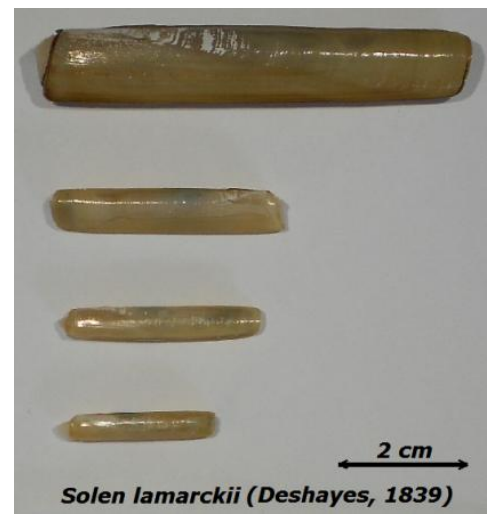

Gambar 1. Solen lamarckii

Jenis Solen sp. yang pernah ditemukan di Indonesia dan telah teridentifikasi antara lain Solen grandis yang ditemukan di Pantai Pamekasan Madura (Nurjanah et al., 2008; Abroni, 2012), Solen vaginalis yang ditemukan di Pantai Timur Surabaya (Trisyani et al., 2008) dan Solen lamarckii yang ditemukan di Pantai Kejawanan Cirebon. Perbedaan spesies Solen ini bisa dilihat dari bentuk dan warna cangkang serta pola pertumbuhannya. Pada Solen lamarckii memiliki warna cangkang coklat dengan pita konsentris pada luar cangkang berwarna keunguan (Poutiers, 1998). 


\section{Parameter lingkungan}

Hasil pengukuran parameter lingkungan pada stasiun 1 adalah :

Tabel 1. Parameter Lingkungan pada Stasiun 1

\begin{tabular}{|c|c|c|c|c|c|c|c|c|}
\hline \multirow[t]{2}{*}{ No. } & \multirow[t]{2}{*}{ Lokasi } & \multirow[t]{2}{*}{$\begin{array}{l}\text { Suhu Air } \\
\qquad\left({ }^{\circ} \mathrm{C}\right)\end{array}$} & \multirow[t]{2}{*}{$\begin{array}{l}\text { Salinitas } \\
\quad(\% 0)\end{array}$} & \multirow[t]{2}{*}{$\mathrm{pH}$} & \multicolumn{2}{|c|}{$\begin{array}{c}\text { Jenis Sedimen } \\
(\%)\end{array}$} & \multirow{2}{*}{$\begin{array}{c}\text { Bahan } \\
\text { Organik } \\
(\%)\end{array}$} & \multirow[t]{2}{*}{$\begin{array}{c}\text { Kepadatan } \\
\left(\text { ind } / \mathrm{m}^{2}\right)\end{array}$} \\
\hline & & & & & Pasir & Lumpur & & \\
\hline 1 & 1.1 & 31 & $24-25$ & 8 & 75,23 & 22,74 & 34,62 & 5 \\
\hline 2 & 1.2 & $32-34$ & $25-27$ & 8 & 75,23 & 22,74 & 32,71 & 19 \\
\hline 3 & 1.3 & 34 & $24-25$ & 8 & 75,23 & 22,74 & 33,61 & 20 \\
\hline 4 & 1.4 & 32 & 30 & 8 & 97,68 & 2,32 & 23,99 & 129 \\
\hline 5 & 1.5 & 32 & 30 & 8 & 97,68 & 2,32 & 27,06 & 137 \\
\hline 6 & 1.6 & 32 & 30 & 8 & 97,68 & 2,32 & 28,00 & 160 \\
\hline 7 & 1.7 & $31-32$ & $29-31$ & 8 & 96,32 & 3,68 & 28,75 & 75 \\
\hline 8 & 1.8 & 31 & $29-30$ & 8 & 96,32 & 3,68 & 28,67 & 93 \\
\hline 9 & 1.9 & 31 & 29 & 8 & 96,32 & 3,68 & 29,00 & 103 \\
\hline \multicolumn{2}{|r|}{$\overline{\mathrm{X}}$} & 31,93 & 28,29 & 8 & 89,74 & 9,58 & 29,60 & 82 \\
\hline \multicolumn{2}{|c|}{ SD } & 0,98 & 2,36 & 0 & 10,90 & 9,89 & 3,42 & 56,64 \\
\hline
\end{tabular}

Sedangkan hasil pengukuran parameter lingkungan pada stasiun 2 adalah :

Tabel 2. Parameter Lingkungan pada Stasiun 2

\begin{tabular}{|c|c|c|c|c|c|c|c|c|}
\hline \multirow[t]{2}{*}{ No. } & \multirow[t]{2}{*}{ Lokasi } & \multirow[t]{2}{*}{$\begin{array}{l}\text { Suhu Air } \\
\left({ }^{\circ} \mathrm{C}\right)\end{array}$} & \multirow[t]{2}{*}{$\begin{array}{l}\text { Salinitas } \\
\text { (\%o) }\end{array}$} & \multirow[t]{2}{*}{$\mathrm{pH}$} & \multicolumn{2}{|c|}{$\begin{array}{c}\text { Jenis Sedimen } \\
(\%)\end{array}$} & \multirow{2}{*}{$\begin{array}{c}\text { Bahan } \\
\text { Organik } \\
(\%)\end{array}$} & \multirow[t]{2}{*}{$\begin{array}{l}\text { Kepadatan } \\
\text { (ind } / \mathrm{m}^{2} \text { ) }\end{array}$} \\
\hline & & & & & Pasir & Lumpur & & \\
\hline 1 & 2.1 & $30-31$ & 25 & 8 & 96,04 & 3,96 & 30,08 & 201 \\
\hline 2 & 2.2 & $31-32$ & $24-26$ & 8 & 96,04 & 3,96 & 30,06 & 184 \\
\hline 3 & 2.3 & $31-32$ & $25-27$ & 8 & 96,04 & 3,96 & 29,26 & 167 \\
\hline 4 & 2.4 & 30 & $26-27$ & 8 & 94,83 & 5,17 & 31,09 & 93 \\
\hline 5 & 2.5 & $30-31$ & $24-26$ & 8 & 94,83 & 5,17 & 31,94 & 74 \\
\hline 6 & 2.6 & 32 & $25-26$ & 8 & 94,83 & 5,17 & 30,31 & 64 \\
\hline 7 & 2.7 & 30 & $27-28$ & 8 & 93,10 & 6,90 & 32,66 & 41 \\
\hline 8 & 2.8 & $31-32$ & 26 & 8 & 93,10 & 6,90 & 32,02 & 36 \\
\hline 9 & 2.9 & $31-32$ & $24-26$ & 8 & 93,10 & 6,90 & 32,08 & 33 \\
\hline \multicolumn{2}{|c|}{$\bar{X}$} & 31,02 & 26,24 & 8 & 94,66 & 5,34 & 31,06 & 99 \\
\hline \multicolumn{2}{|c|}{ SD } & 0,77 & 1,41 & 0 & 1,28 & 1,28 & 1,18 & 66,92 \\
\hline
\end{tabular}

Hasil pengukuran parameter lingkungan berupa parameter fisika perairan dan kandungan bahan organik di kedua stasiun menunjukan Pantai Kejawanan masih dalam kondisi yang baik untuk pertumbuhan dan perkembangan kerang pisau secara optimal. Kisaran nilai parameter fisika pada pengambilan sampel di stasiun 1 suhu berkisar antara $31-34$ ${ }^{\circ} \mathrm{C}$, salinitas berkisar antara $24-31 \%$ dan $\mathrm{pH}$ memiliki nilai 8 . Pada stasiun 2 nilai suhu berkisar antara $30-32{ }^{\circ} \mathrm{C}$, salinitas antara $24-28 \%$ dan nilai $\mathrm{pH}$ 8. Nilai tersebut merupakan kisaran nilai parameter fisika yang mendukung kehidupan kerang. Menurut Braley (1992) kehidupan optimal kerang pada suhu $25-32{ }^{\circ} \mathrm{C}$ dan $\mathrm{pH} 7,9-8,2$. Nilai kandungan bahan organik di Pantai Kejawanan pada kedua stasiun tergolong tinggi yaitu sebesar 29,60\% pada stasiun 1 dan 31,06 \% pada stasiun 2. Menurut Reynold (1971) dalam Perdana (2012) kandungan bahan organik klasifikasi tinggi yaitu berkisar antara $17-35 \%$.

\section{Jenis sedimen}

Jenis sedimen yang ada di Pantai Kejawanan tergolong kategori pasir berlumpur dengan didominasi oleh pasir. Berdasarkan Phi scale Wentworth sedimen pasir di Pantai Kejawanan merupakan jenis medium sand yaitu pasir dengan diameter butir antara 0,25 - 0,50 mm (Hutabarat dan Evans, 1985). Adanya sedimen pasir pada suatu wilayah pantai diakibatkan oleh gelombang yang membawa partikel-partikel pasir, pecahan batuan dan karang ke pantai tersebut, hal ini memungkinkan Pantai Kejawanan memilki sedimen pasir akibat gelombang Laut Jawa yang membawa partikelpartikel sedimen pasir.

Persentase pasir yang ada pada stasiun 2 lebih tinggi daripada stasiun 1, hal ini disebabkan pada stasiun 1 berdekatan dengan vegetasi mangrove yang memiliki jenis sedimen berlumpur. Melihat dari penelitian yang dilakukan Rifni (2010) yang menyatakan bahwa Pantai Kejawanan memiliki tipe pasang surut campuran condong harian ganda (mixed tide predominantly semi diurnal) artinya dalam satu hari terjadi dua kali air pasang dan dua kali air surut dengan tinggi dan periode berbeda dimana waktu pasang lebih lama daripada waktu surut. Sehingga daerah pantai lebih lama 
terendam air laut, hal ini berakibat sedimen lumpur dari vegetasi mangrove banyak bercampur dan mempengaruhi jenis sedimen pada stasiun 1 .

Sedimen lumpur di Pantai Kejawanan juga dipengaruhi oleh masukan beberapa sungai yang berada dekat dengan Perairan Kejawanan, antara lain Sungai Cimanuk, Sungai Tangkal dan Sungai Pegambiran (Irfan, 2011). Aliran sungai cenderung membawa material sedimen halus yang berasal dari erosi di daratan menuju ke wilayah laut. Keberadaan sedimen lumpur dipengaruhi oleh banyaknya partikel tersuspensi yang terbawa oleh air tawar, serta faktor-faktor yang mempengaruhi penggumpalan dan pengendapan bahan tersuspensi tersebut, seperti adanya arus dari laut (Abroni, 2012).

\section{Sebaran kerang pisau}

Sebaran kerang pisau di Pantai Kejawanan bersifat mengelompok pada jenis sedimen tertentu. Kerang ini banyak ditemukan pada jenis sedimen pasir berlumpur. Jenis sedimen pasir berlumpur merupakan habitat kerang pisau. Hal ini sesuai dengan hasil penelitian Trisyani et al. (2007) yang menyatakan bahwa kerang pisau menyukai habitat sedimen pasir berlumpur.

Sebaran individu yang mengelompok disebabkan biota tersebut memilih hidup pada habitat yang paling sesuai, baik sesuai dengan faktor fisika-kimia perairan maupun tersedianya makanan. Suin (1989) dalam Prasojo et al. (2012) menyatakan bahwa faktor fisika dan kimia yang merata pada suatu habitat serta tersedianya makanan bagi biota yang hidup didalamnya menentukan biota tersebut hidup berkelompok.

\section{Pengaruh jenis sedimen terhadap sebaran kerang pisau}

Kerang pisau ditemukan pada jenis sedimen pasir berlumpur, semakin tinggi kandungan pasir pada sedimen maka semakin tinggi kepadatannya. Jenis sedimen pasir mempunyai pertukaran air yang cepat sehingga menambah persediaan oksigen dan merupakan penyangga yang baik bagi perubahan suhu dan salinitas yang besar (Abroni, 2012). Adanya campuran lumpur cenderung mengakumulasi bahan organik. Bahan organik ini dimanfaatkan oleh fitoplankton yang merupakan sumber makanan bagi kerang pisau.

Kerang ini menyukai habitat sedimen pasir berlumpur disebabkan morfologi kerang yang memanjang dan memiliki pola hidup dengan cara menggali ke dalam sedimen. Dari pola tersebut sedimen pasir sangat memungkinkan untuk ditinggali, karena pada sedimen ini memiliki pore water lebih besar, sehingga tekanan yang dihasilkan juga lebih besar. Tekanan tersebut akan mempermudah dalam pergerakan kerang untuk masuk atau keluar sedimen.

Adanya perbedaan kepadatan kerang antara stasiun 1 dan stasiun 2 disebabkan kualitas habitat yang berbeda pada kedua stasiun. Pada stasiun 2 kepadatan kerang yang ditemukan lebih tinggi daripada stasiun 1, hal ini dikarenakan pada stasiun 2 memiliki jenis substrat yang lebih berpasir daripada stasiun 1. Selain itu rata-rata kandungan bahan organik yang ada pada stasiun 2 lebih tinggi daripada stasiun 1, dimana bahan organik akan mempengaruhi ketersediaan makanan pada stasiun tersebut.

\section{Pengolahan data citra Satelit Landsat ETM}

Pengolahan ini dibuat berdasarkan data lapangan dengan perhitungan geostatistik kriging. Data tersebut kemudian ditumpang susun (overlay) dengan citra Satelit Landsat ETM daerah Pantai Kejawanan Cirebon. Peta yang dihasilkan dari proses ini antara lain: peta kepadatan kerang pisau, peta sebaran sedimen pasir, peta sebaran sedimen lumpur dan peta kandungan bahan organik.

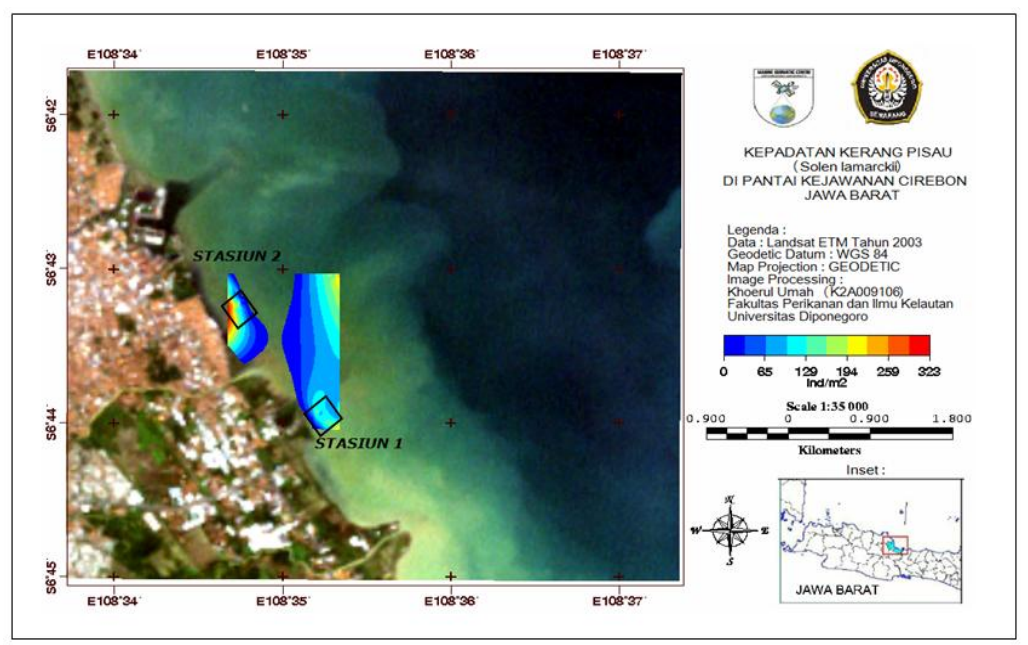

Gambar 2. Peta Kepadatan Kerang Pisau (ind $/ \mathrm{m}^{2}$ ) di Pantai Kejawanan 


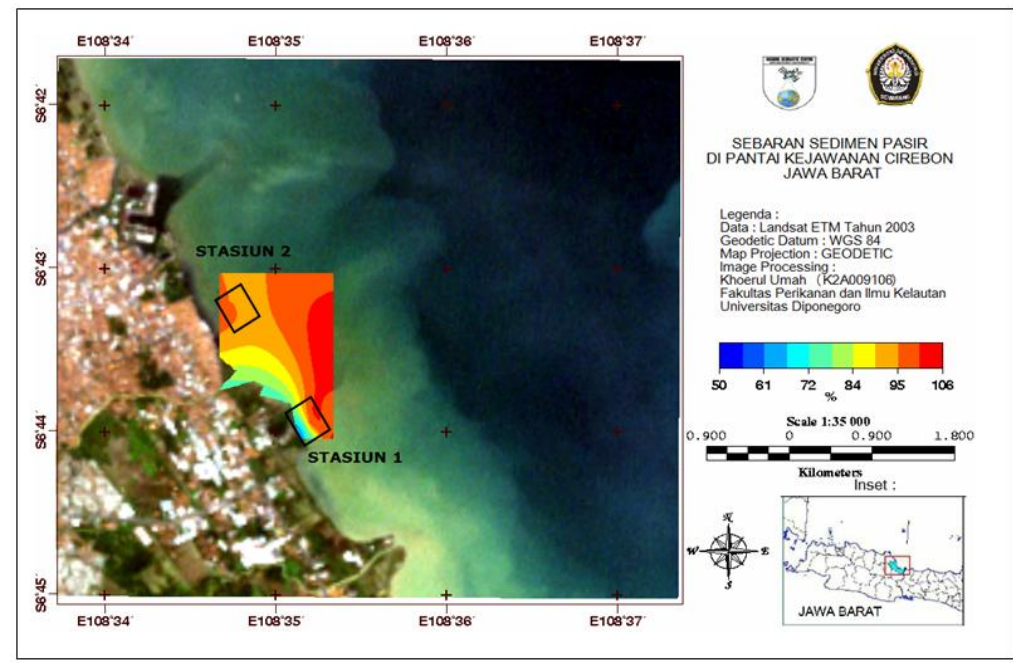

Gambar 3. Peta Sebaran Sedimen Pasir (\%) di Pantai Kejawanan

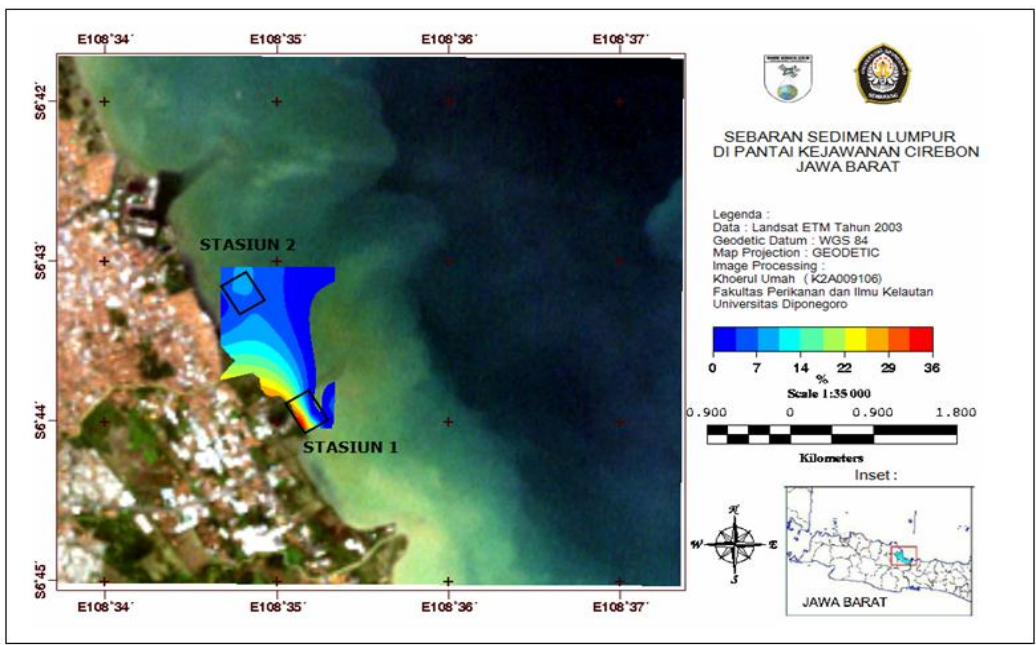

Gambar 4. Peta Sebaran Sedimen Lumpur (\%) di Pantai Kejawanan

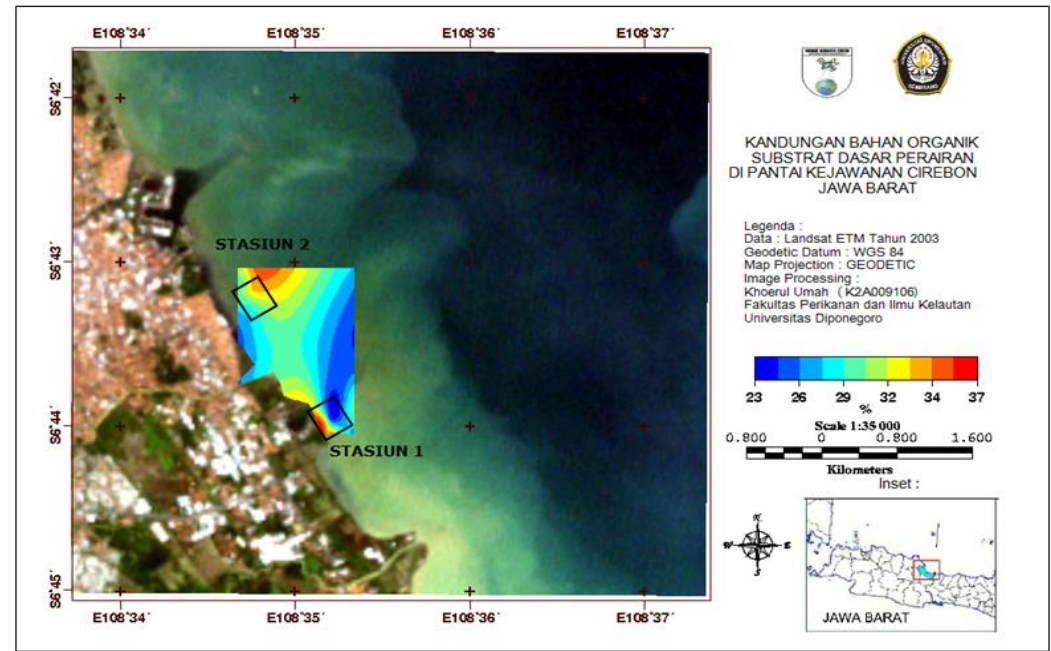

Gambar 5. Peta Kandungan Bahan Organik (\%) di Pantai Kejawanan

\section{Analisis data}

Hasil yang didapatkan pada analisis data berupa uji statistik antara lain :

\section{a. normalitas data}


Hasil pengujian normalitas data dengan menggunakan uji statistik menunjukkan data tersebar normal dengan nilai sig. pada ketiga variabel $>\alpha(0,05)$. Normalitas dipenuhi jika hasil uji tidak signifikan untuk suatu taraf signifikansi $(\alpha)$ tertentu (Candiasa, 2003 dalam Perdana, 2012).

\section{b. korelasi antara panjang dan berat}

Hasil pengujian korelasi antara panjang dengan berat kerang pisau didapatkan angka hubungan korelasi 0,994 yang artinya korelasi sangat signifikan karena mendekati 1 . Untuk nilai signifikan sebesar $0,000<0,05$ sehingga terdapat hubungan nyata antara panjang kerang dengan beratnya. Hal ini artinya semakin panjang kerang maka akan semakin berat kerang tersebut (Walpole, 1995 dalam Abroni, 2012). Rata-rata panjang dan berat kerang pada stasiun 1 lebih tinggi daripada stasiun 2 artinya pada stasiun 1 memiliki jumlah kerang dengan usia dewasa (mencapai ukuran panjang maksimal) lebih banyak daripada stasiun 2 .

c. regresi linier antara kepadatan terhadap jenis sedimen pasir

Hasil uji regresi linier pada pengujian kepadatan terhadap jenis sedimen pasir menunjukan nilai koefisien korelasi sebesar 0,673 yang mengindikasikan korelasi antara kepadatan dengan jenis sedimen pasir kuat. Nilai $F$ hitung yang didapatkan sebesar 13,258 > F Tabel 4,49 dengan $\alpha=0,05$, maka $\mathrm{H}_{0}$ ditolak dan $\mathrm{H}_{1}$ diterima. Hal ini berarti koefisien regresi antara kepadatan terhadap sedimen pasir signifikan, berarti ada pengaruh dari jenis sedimen terhadap kepadatan kerang. Persamaan linier yang didapatkan adalah $\mathrm{Y}=-384,358+5,154 \mathrm{X}$.

d. regresi linier antara kepadatan terhadap kandungan bahan organik

Pada pengujian regresi linier antara kepadatan terhadap kandungan bahan organik, nilai koefisien korelasi yang didapatkan sebesar 0,669 menunjukan hubungan yang kuat antara kepadatan terhadap kandungan bahan organik. Nilai F hitung yang didapatkan sebesar 12,961 > F Tabel 4,49 dengan $\alpha=0,05$. Pada pengujian tersebut tolak $\mathrm{H}_{0}$ terima $\mathrm{H}_{1}$, yang berarti terdapat hubungan antara kepadatan dengan kandungan bahan organik. Persamaan linier yang didapatkan adalah $\mathrm{Y}=-567,326+15,711 \mathrm{X}$.

e. regresi linier berganda antara kepadatan terhadap jenis sedimen pasir dan kandungan bahan organik

Hasil pengujian pada uji statistik menggunakan regresi linier berganda antara kepadatan terhadap sedimen pasir dan kandungan bahan organik mendapatkan nilai koefisien korelasi sebesar 0,726. Angka ini menunjukan adanya korelasi yang kuat antar kepadatan terhadap jenis substrat dan kandungan bahan organik. Sementara untuk nilai $\mathrm{F}$ hitung yang didapatkan sebesar 8,358 $>$ F Tabel 3,68 dengan $\alpha=0,05$, sehingga tolak $\mathrm{H}_{0}$ dan terima $\mathrm{H}_{1}$. Hal ini berarti parameter lingkungan berupa jenis sedimen dan kandungan bahan organik mempengaruhi kepadatan kerang pisau. Persamaan linier yang didapatkan adalah $\mathrm{Y}=-83,157+3,061 \mathrm{X}_{1}+9,054 \mathrm{X}_{2}$.

\section{Kesimpulan}

Berdasarkan hasil penelitian yang telah dilakukan dapat diambil kesimpulan sebagai berikut :

1. Jenis sedimen yang ada di Pantai Kejawanan adalah jenis pasir berlumpur (medium sand) dengan persentase pasir antara 75,23 - 96,04\% dan lumpur antara 3,96 - 22,74\%.

2. Sebaran kerang pisau di Pantai Kejawanan bersifat mengelompok dan hanya ditemukan pada jenis sedimen tertentu.

3. Pada jenis sedimen pasir berlumpur dengan persentase kandungan pasir yang tinggi kepadatan kerang juga tinggi. Sedangkan pada persentase kandungan pasir yang rendah kepadatannya rendah.

\section{Daftar Pustaka}

Abroni, K. 2012. Analisa Spasial Distribusi Kerang Pisau (Solen grandis) dan Sebaran Sedimen dengan menggunakan Data Citra Satelit Landsat di Pantai Mangunan Kecamatan Pademawu Kabupaten Pamekasan, Madura. [Skripsi]. Program Studi Manajemen Sumberdaya Perairan. Fakultas Perikanan dan Ilmu Kelautan. Universitas Diponegoro. Semarang.

Braley, R. D. 1992. The Giant Clams: A Hatchery and Nursery Culture Manual. Australian Centre for International Agricultural Research (ACIAR) Monograph. Canberra.

Dinas Pelabuhan Perikanan Nusantara Kejawanan, Cirebon, Jawa Barat. Profil PPN Kejawanan 2009. http://ppnkejawanan.blogspot.com/2009/11/profil-2009.html. (Diakses tanggal 18 Desember 2012).

Hartoko, A. 2010. Oseanografi dan Sumberdaya Perikanan - Kelautan Indonesia. UNDIP Press. Semarang. ISBN : $978-$ 979-704-892-1.

Http://www.usgs.glovis.gov. 2003. Landsat ETM. (Diakses tanggal 11 Maret 2013).

Hutabarat, S. dan S. M. Evans. 1985. Pengantar Oseanografi. UI-Press. Jakarta.

Indrawati, A. 2013. Analisa Klorofil-a, Nitrat dan Fosfat pada Vegetasi Mangrove Berdasarkan Data lapangan dan Data Satelit Geoeye di Pulau Parang, Kepulauan Karimujawa. [Skripsi]. Program Studi Manajemen Sumberdaya Perairan. Fakultas Perikanan dan Ilmu Kelautan. Universitas Diponegoro. Semarang.

Irfan. 2011. Laporan Praktikum Sedimentologi. Program Studi Ilmu Kelautan. Universitas Padjadjaran. Bandung.

Nurjanah, Kustiariyah dan S. Rusyadi. 2008. Karakteristik Gizi dan Potensi Pengembangan Kerang Pisau (Solen spp) di Perairan Kabupaten Pamekasan Madura. Jurnal Perikanan dan Kelautan. 13(1): 41-51. 
Perdana, S. A. 2012. Hubungan Akumulasi Bahan organik Tanah Terhadap Kadar Amonia dan Nitrit pada Tambak Intensif Udang Windu (Penaeus monodon Fabricius, 1798) di BBPBAP Jepara. [Skripsi]. Program Studi Manajemen Sumberdaya Perairan. Fakultas Perikanan dan Ilmu Kelautan. Universitas Diponegoro. Semarang.

Poutiers, J. M. 1998. Bivalves (Acephala, Lamellibranchia, Pelecypoda). In Carpenter, K. E. and V. N. Niem (eds.). FAO Species Identification Guide for Fisheries Purpose. The Living Marine Resources of the Western Central Pacific. Vol. 1. Seaweeds, Corals, Bivalves and Gastropods. FAO of the United Nations, Rome.

Prasojo, S. A., Irwani dan C. A. Suryono. 2012. Distribusi dan Kelas Ukuran Panjang Kerang Darah (Anadara grandosa) di Perairan Pesisir Kecamatan Genuk, Kota Semarang. Jurnal of Marine Research. 1(1):137-145.

Rifni, D. 2010. Laporan Praktikum Oseanografi Fisika. Program Studi Ilmu Kelautan. Universitas Padjadjaran. Bandung.

Riniatsih, I. dan E. W. Kushartono. 2009. Substrat Dasar dan Parameter Oseanografi sebagai Penentu Keberadaan Gastropoda dan Bivalvia di Pantai Sluke Kabupaten Rembang. Jurnal Ilmu Kelautan Universitas Diponegoro. 14(1): 50-59.

Sarwono, J. 2006. Metode Penelitian Kuantitatif dan Kualitatif. Graha Ilmu. Yogyakarta.

Sukmadinata. 2006. Metode Penelitian Pendidikan. Rosdakarya. Bandung.

Trisyani, N., B. Irawan dan N. Rosana. 2007. Faktor Lingkungan Yang Mempengaruhi Kepadatan Lorjuk (Solen vaginalis) Di Perairan Pantai Timur Surabaya. Prosiding Seminar Nasional Moluska Dalam Penelitian, Konservasi dan Ekonomi. Universitas Diponegoro. Semarang. 168-174.

Umar, H. 1999. Metodologi Penelitian. PT. Gramedia Pustaka Utama. Jakarta. 